\title{
Decisions, decisions...
}

\section{How We Decide/The Decisive Moment by Jonah Lehrer \\ Houghton Mifflin Harcourt/Canongate: 2009. 320 pp./304 pp. $\$ 25 / € 16.99$}

"I was flying a Boeing 737 into Tokyo when the left engine caught on fire," begins Jonah Lehrer in his captivating book on decision-making. What should a pilot do? The right decision will make the difference between life and death. Luckily, Lehrer was piloting a simulator and could replay his decisions. But how do you decide when you don't get another chance? How We Decide uses the lessons of decision-making research to help us make better choices.

Lehrer asks if good decisions are always reached by extensive rational deliberations, or if we should sometimes rely on our automatic, emotional reactions. When is it best to use our gut instincts and when should we stop and reason? He organizes his answer around vivid anecdotes, each highlighting key concepts from psychology and behavioural economics. Lehrer is an expert storyteller, often using dramatic examples from aviation to highlight how rapid gut reactions averted one crash, whereas emotional control and reasoned, outside-the-box thinking by pilots let them survive in others.

Sometimes it is best to stop thinking altogether. When trying to make optimal choices based on a large number of attributes, such as picking a car or a house, people are less accurate when left to ponder for a few minutes than when they are distracted for a similar period. One interpretation is that conscious thought is at a disadvantage when processing many attributes in parallel, owing to limitations in capacity. Such examples remind us of the limits of our deliberative decision-making processes.

Lehrer considers any decision that is not executed according to the rules of logic to be "irrational". But in many cases these only show the limitations of laboratory studies. The book fails to note relevant perspectives from behavioural economics and game theory, according to which many emotions are rational evolutionary adaptations that have essential roles in cooperative behaviours and social interaction. More problematic is Lehrer's insistence on attributing decisions to either an emotional brain or a rational one. There is no evidence that the brain has distinct and opposing emotional and rational regions. A case in point is the dopamine system. Although described in the book as emotional, our current understanding is that it is rational: dopamine neurons signal a simple and computationally well-defined variable the reward prediction error - and broadcast it

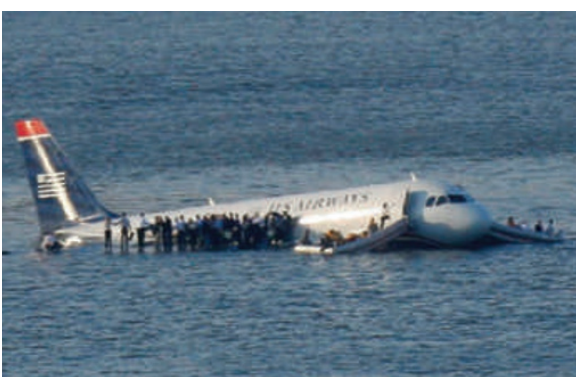

A fast-thinking pilot saved lives by landing his plane on the Hudson River in New York.

throughout the brain. This simplification of the complex function of the dopamine system is a major success story of neuroscience. As it turns out, the process by which these neurons signal errors may be suboptimal, but that does not make it irrational or emotional.

Lehrer has a tendency to present a caricature view of brain processing. For example, the nucleus accumbens "might want the George Foreman grill, but the insula knows that you can't afford it, or the prefrontal cortex realizes that it's a bad deal. The amygdala might like Hillary Clinton's tough talk on foreign policy, but the ventral striatum is excited by Obama's uplifting rhetoric."

Such neurobabble has unfortunately become commonplace in science journalism. Lehrer is following a well-established lingo - and some blame lies with the scientific community for tolerating, if not encouraging, this trend. Until recently we could not study a functioning human brain. All we had were the accidental lesions of patients whose tragic stories illuminated the functions of their missing brain regions. Recent advances in neuroscience dramatically changed this situation - but in this book the visual appeal of neuroimaging studies is often used as a substitute for the lessons learned. It is exciting to observe the nucleus accumbens 'lighting up' in a brain scan when a reward is provided, but this is not an explanation for 'wanting' and misses the subtler yet more enlightening findings about reward processing in the brain.

Lehrer aims high by applying lessons from the neuroscience of decision-making to everyday choices. He provides valuable - if obvious advice, such as relying on gut instinct for unimportant decisions but on reason when faced with new problems. But we were promised insights from neuroscience, not age-old wisdom.

Neuroscientists must grapple with how to communicate subtle conclusions in a world of headline-news reporting. Popular books such as this one could serve this goal of translating science for the public. But by smoothing out the rough edges of our knowledge, Lehrer leads the reader astray. Among his well-told dramatic stories the science often gets lost. Yet he is a gifted writer, so I hope for his next project he will dig deeper, embrace complexity and make it his job to report from the cuttingedge of scientific knowledge.

Adam Kepecs is assistant professor of neuroscience at Cold Spring Harbor Laboratory, New York 11724, USA.

e-mail:kepecs@cshl.edu

\section{Songs on the brain}

\section{Rock-It Science \\ Concert at the Highline Ballroom, New York 3 March 2009}

Swapping his microscope for a microphone, New York University neuroscientist Joseph LeDoux (pictured, right) took to the stage of the Highline Ballroom, a Manhattan music club. Leading his folk rock band, LeDoux articulated each line of his science-inspired songs with conviction, accompanied by electric guitar. His group, The Amygdaloids, featured heavily at Rock-It Science, a concert held last month to raise funds for research into sensoryprocessing disorders.

The charity concert, the brainchild of LeDoux and co-organized with psychologist Jennifer Jo Brout of the Sensation and Emotion Network in New York, mixed scientists with

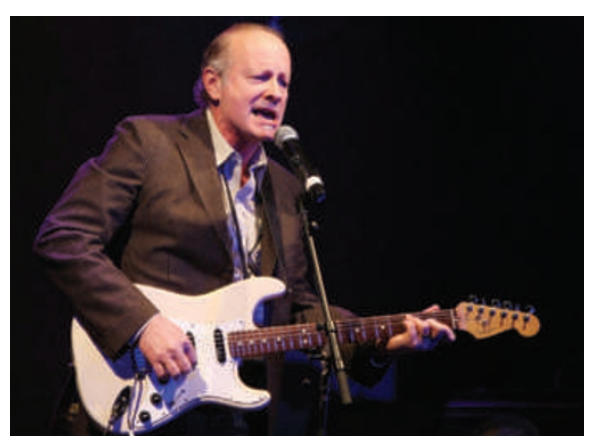

professional musicians, and was headlined by singer-songwriter Rufus Wainwright.

LeDoux, who studies the biological mechanisms underlying emotional memory, sees rock 'n' roll as a perfect vehicle for inspiring interest in neuroscience. "All our songs have a mind-brain angle. We believe we can interest someone in tough concepts through music." 